\title{
Effect of hot-rolling in the austenitic region on the formation of isothermal bainite in a $0.4 \mathrm{C}-1.5 \mathrm{Si}-1.4 \mathrm{Mn}$ steel
}

\author{
E. Girault, S. Godet ${ }^{1}$, P. Jacques ${ }^{1,2}$, Ph. Bocher, B. Verlinden \\ and J. Van Humbeeck
}

Department of Metallurgy and Materials Engineering, K.U. Leuven, De Croylaan 2, 3001 Leuven, Belgium

${ }^{1}$ Université Catholique de Louvain, Département des Sciences des Matériaux et des Procédés, PCIM, place Sainte-Barbe 2, 1348 Louvain-la-Neuve, Belgium

${ }^{2}$ Mc Gill University, Department of Metallurgical Engineering, 3610 University Street, Montreal H3A 2B2, Québec, Canada

\begin{abstract}
This paper aims to give further insights on the changes that are brought on bainite formation by prior hot-deformation. To this end, a thermomechanical treatment was performed on blocks of a $0.4 \mathrm{C}-1.5 \mathrm{Si}-1.4 \mathrm{Mn}$ steel. The chemistry of this alloy allowed hot-rolling in the full austenitic range up to large reductions without any significant recrystallisation. The deformed plates were then partially transformed to bainite and the resulting microstructures were subjected to investigation. The laths of bainitic ferrite appeared to be grouped in packets in which they exhibit the same crystallographic orientation. When no prior hot-deformation is applied, the bainite packets originating from the same austenite parent grain were randomly distributed. However, severely deformed austenite grains were found to give rise to typical orientations of the bainitic ferrite laths. These results were interpreted in terms of dislocation arrays interacting with a displacive transformation.
\end{abstract}

\section{INTRODUCTION}

Recent investigations have evidenced the incontestable interest of the bainitic transformation for stabilising austenite in low alloy steels. This has notably led to the development of multiphase TRIP. assisted steels, whose exceptional mechanical properties are mainly due to the presence of retained austenite in their microstructure [1]. However, most of the studies have focussed so far on cold-rolled and continuously annealed steels, the isothermal bainitic stage being performed during this heattreatment. Another processing route consists in applying the bainitic holding just after the hot-rolling passes, so that the alloy is manufactured in one shot. Despite the potential interest of this technique, a lack of knowledge still remains about the influence of the hot-deformation on the development of the microstructure. In this respect, the present contribution is intended to assess how and to which extent bainite is affected by the occurrence of prior rolling in the austenitic field.

\section{MATERIAL FEATURES AND EXPERIMENTAL PROCEDURE}

A vacuum melted steel ingot was the starting material for this work. Its chemistry is given in table 1.

Table 1: Chemical composition (wt.\%) of the steel investigated.

\begin{tabular}{lccccccc}
\hline Element & $\mathbf{C}$ & $\mathbf{S i}$ & $\mathbf{M n}$ & $\mathbf{A l}$ & $\mathbf{P}$ & $\mathbf{S}$ & $\mathbf{N}$ \\
\hline wt. \% & 0.39 & 1.45 & 1.37 & 0.05 & 0.012 & 0.006 & 0.003 \\
\hline
\end{tabular}

The as-cast ingots were cut in small blocks of about $120 \times 40 \times 10 \mathrm{~mm}$, on which the thermomechanical treatment presented in figure 1 was applied. The hot-rolling process was conducted using a laboratory hot-rolling mill. The temperature of the hot steel plate was measured before and after each rolling pass, using two pyrometers. The material was first solutionised in a muffle furnace at $1250^{\circ} \mathrm{C}$ for 30 minutes to allow the complete dissolution of carbides and the achievement of a full austenitic microstructure. The specimen was then removed from the furnace and air-cooled to $1000^{\circ} \mathrm{C}$. At this temperature, a refinement of the microstructure by recrystallisation was achieved by applying 
$50 \%$ thickness reduction in one rolling pass. After this roughing process, the slab was then air-cooled again to $750^{\circ} \mathrm{C}$. At this temperature, a single rolling pass was performed leading to a reduction between 0 and $55 \%$. According to dilatometry measurements, the Ar3 temperature is about $680^{\circ} \mathrm{C}$, so that the microstructure present during rolling at $750^{\circ} \mathrm{C}$ is likely to be still fully austenitic. After rolling, the sheet was rapidly transferred to a lead bath furnace at $400^{\circ} \mathrm{C}$. Figure 2 shows that, even after large deformations, the static recrystallisation of austenite grains remains very limited below 5 seconds. The experimental time required to transfer the plate to the lead bath furnace is evidently less and the hot-deformation process is therefore expected to give rise to a structure of deformed austenite grains.

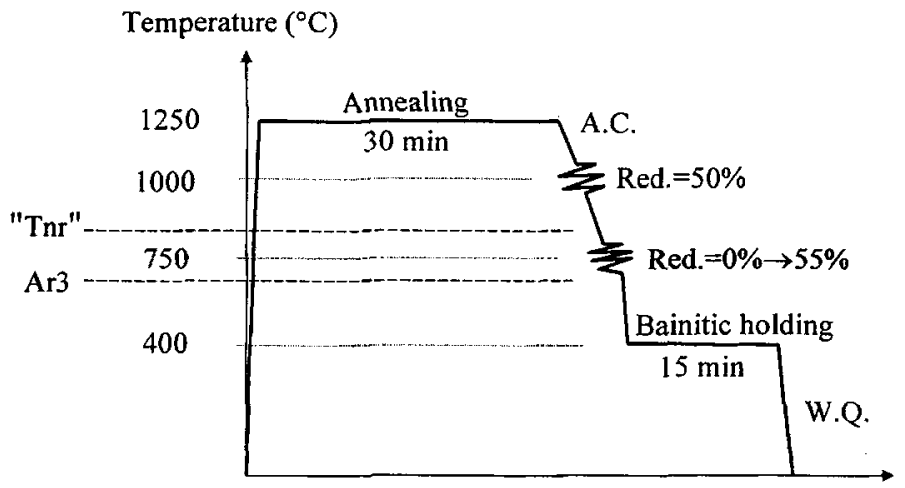

Time

Figure 1: Thermomechanical scheme performed on the as-cast blocks.

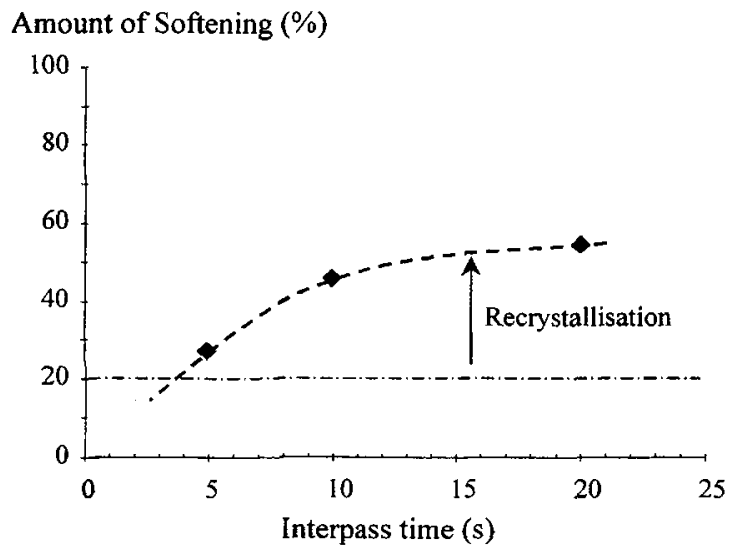

Figure 2: Amount of softening vs. interpass time for hot-torsion testing. The specimen is first deformed at $750^{\circ} \mathrm{C}$ (pass 1 ) then relaxed during the interpass time and deformed again (pass 2). The deformations applied are equivalent to a thickness reduction of $55 \%$ in rolling conditions. The amount of softening is defined as the difference between TSI and YS2 normalised by TSI-YS1, where YS and TS refer respectively to the yield stress and the tensile stress obtained during the passes. Generally, recovery is believed to contribute to about $20 \%$ of the softening whereas $10 \%$ minimum of recrystallisation is necessary to be detected.

The cooling rate accompanying the fast transfer of the hot-deformed plate to the lead bath furnace is sufficiently high to prevent any major formation of proeutectoid ferrite. The microstructure is 
therefore directly brought to a temperature region in which the bainitic transformation can take place. During this stage, the specimen is held at $400^{\circ} \mathrm{C}$ for 15 minutes, which is believed to be sufficient for the bainite formation to go to its completion. In order to investigate the isothermal microstructure generated during the bainitic holding, the sample is finally water-quenched to room temperature.

The samples obtained were classically mounted, ground and polished for further analyses. Examinations by Scanning Electron Microscopy (SEM) were completed by Orientation Image Microscopy (OIM). To this end, the specimens were electropolished in a solution of acetic acid and acid perchloric $(5 \%)$ operating at room temperature and $40 \mathrm{~V}$. The OIM scans were obtained using a Philips FEG-SEM and an OIM with the standard TexSem® ${ }^{\circledR}$ software. The OIM was operated at $15 \mathrm{kV}$ and a step size of $0.2 \mu \mathrm{m}$. Bulk texture measurements were obtained by the inversion of four incomplete X-ray poles figures. Orientation Distribution Functions (ODF) were then calculated using the MTM-FHM software [2].

\section{RESULTS AND DISCUSSION}

Figure 3 displays a representative portion of the microstructure that is obtained when no hotdeformation is applied at $750^{\circ} \mathrm{C}$. Under these conditions, the microstructure simply consists of laths of bainitic ferrite separated from each other by interlath compounds, mainly retained austenite. As shown in figure $3 b$, the laths of bainitic ferrite are grouped in packets in which they exhibit the same crystallographic orientation. The absence of proeutectoid ferrite is consistent with the measured Ar3 temperature and makes the recognition of the former austenite grain boundaries by simple SEM examinations a cumbersome task (see figure $3 \mathrm{a}$ ). However, the OIM technique allows the determination of the crystallographic orientation of retained austenite islands, since in an original OIM colour map all the remnants of each single former austenite grain exhibit the same colour. In this way, it becomes feasible to find the former austenite boundaries [3] and to represent them as displayed in figure 3. The grains delineated are equiaxed, which confirms the complete recrystallisation of the austenite after the first rolling pass at $1000^{\circ} \mathrm{C}$. Bulk texture measurements on the sample failed to evidence any strong texture component, neither for the retained austenite nor for the bainitic ferrite. In agreement with this random distribution, each former austenite grain proves to have generated a large variety of bainite packets. Figure $3 \mathrm{~b}$ shows indeed the presence of numerous bainite packets with a large spread of colour, i.e. with various crystallographic orientations, within each individual parent austenite grain. On the other hand, figure $3 \mathrm{a}$ indicates that this random crystallographic distribution is also accompanied with a random geometrical distribution of the bainite laths, which may grow in all possible directions in the original austenite grain.

Figure 4 represents a characteristic portion of the microstructure that is achieved when a rolling reduction of $55 \%$ is performed at $750^{\circ} \mathrm{C}$. The layout applied is similar to figure 3 , which makes the comparison straightforward. The microstructure presents a very small amount of proeutectoid ferrite at former austenite grain boundaries, certainly due to an activation of the nucleation process on some of the dislocations introduced by hot-deformation. However, the formation of this equiaxed ferrite grains seems very limited and turns out to be quite useful for the delineation of the former austenite grains. The latter appear therefore elongated along the rolling direction, thereby confirming that the second rolling pass is well conducted under the Tnr temperature. A further evidence of this is brought by the ODF's sections of the retained austenite displayed in figure 5 . The texture of the austenite is mainly composed of Goss and $\beta$-fiber components, which are typical of "pancaked" austenite $[4,5]$. The bainitic ferrite, in turn, was also found to exhibit a sharp texture, as can be seen in figure $4 \mathrm{~b}$. The OIM scan indeed reveals that severely deformed austenite parent grains give rise to bainite packets that corresponds in fine to a very limited range of crystallographic orientations. Accordingly, in the microstructure presented, each former austenite boundary encompasses only a couple of discrete colour levels. This selective bainitic ferrite formation is also geometrical since it appears on figure $4 \mathrm{a}$ that the bainite laths form along preferential directions that correspond to angles lying between $30^{\circ}$ and $40^{\circ}$ to the rolling direction. 

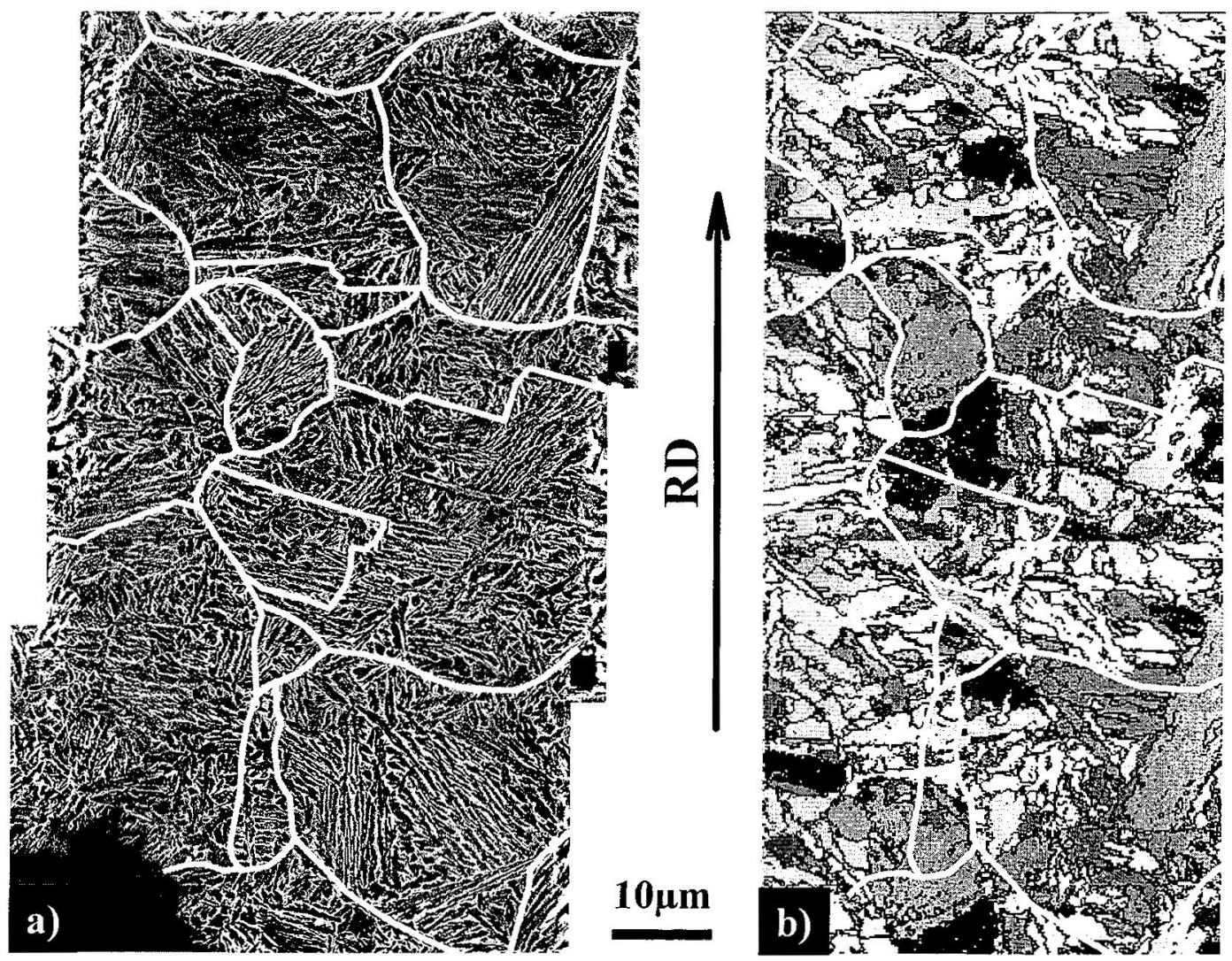

Figure 3: SEM micrograph (a) and corresponding OIM scan (b) of a representative area of the microstructure when no deformation is performed at $750^{\circ} \mathrm{C}$. The white solid lines represent the former austenite grain boundaries. The plane of section is transverse to the plate along the rolling direction (RD). The region investigated is located at half of the thickness of the plate.

Figure 6 shows the microstructure of a plate that was rolled at $750^{\circ} \mathrm{C}$ with a reduction of $25 \%$, slowly cooled to $30^{\circ} \mathrm{C}$ below $\mathrm{Ar} 3$ and then water-quenched. By so doing, martensite is formed from austenite grains whose boundaries have been highlighted by proeutectoid ferrite. Preliminary hottorsion tests verified the absence of austenite recrystallisation for equivalent moderate hotdeformations. Martensite is found to display the same geometrical features as mentioned earlier for bainite, i.e. an orientation selection of the laths at about $35^{\circ}$ to the rolling direction. The similar behaviour observed for both martensite and bainite is in agreement with a displacive rationalisation of the bainitic transformation. The angle between the bainite/martensite laths and the rolling direction is of the same order as the macroscopic orientations of the dislocation walls that have been reported to form during rolling of fcc metals $[6,7]$. These dislocation walls, like any other crystal defect, are known to impede the growth of the laths occurring by a displacive transformation [8]. In the present case, it is likely that the bainite laths can only develop along the direction for which they have the lowest probability to meet dislocations, namely in between the dislocation walls. It is believed thus that the bainite formed after a hot-deformation follows the array of the dislocation walls. Accordingly, large rolling reductions give rise to an alignment of the bainitic ferrite laths and to a refinement of the microstructure, as observed in figures 3 and 4. 

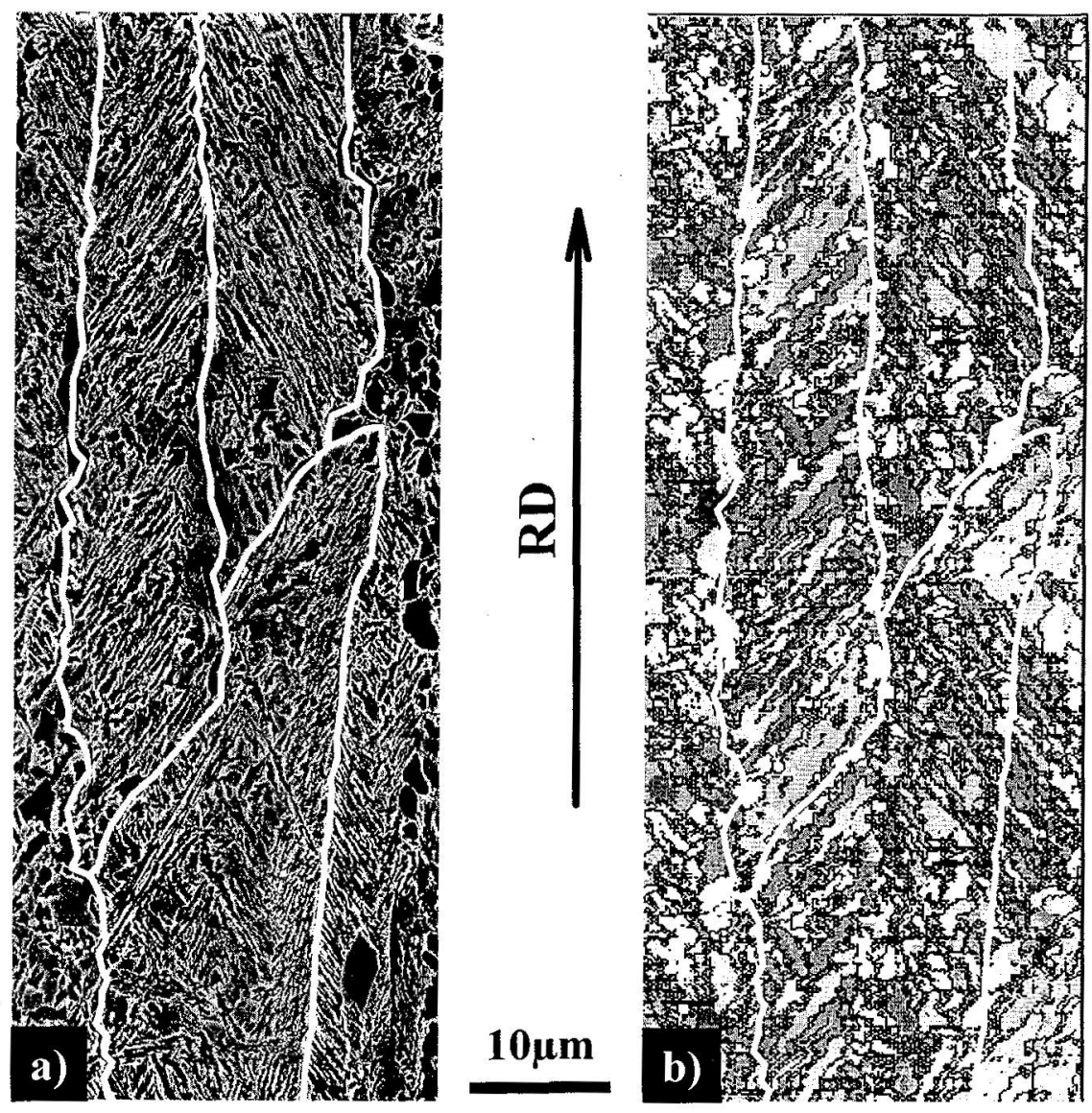

Figure 4: SEM micrograph (a) and corresponding OIM scan (b) of a representative area of the microstructure when $55 \%$ rolling reduction is performed at $750^{\circ} \mathrm{C}$. The white solid lines represent the former austenite grain boundaries. The plane of section is transverse to the plate along the rolling direction (RD). The region investigated is located at half of the thickness of the plate.
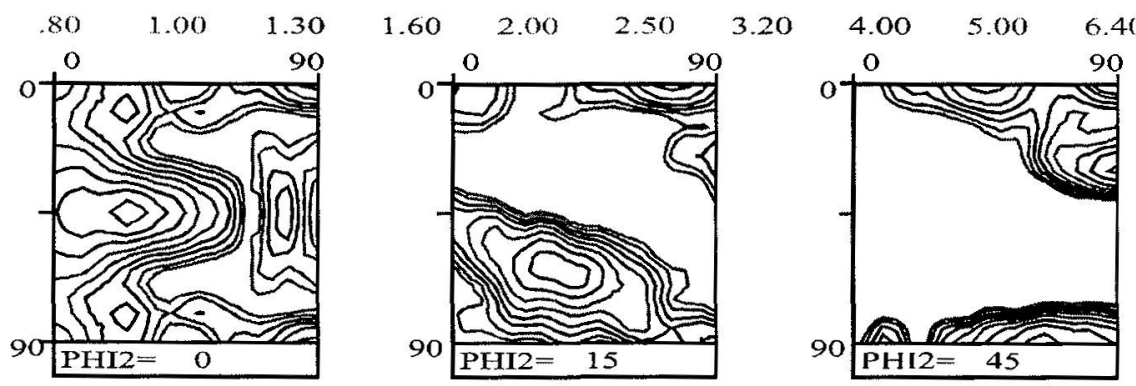

Figure 5: 0,15 and $45^{\circ} \Phi 2$ sections of the X-ray ODF's for retained austenite when $55 \%$ rolling reduction is performed at $750^{\circ} \mathrm{C}$. The function values are represented by means of contour lines, and the contour levels are listed on top. The measurements were performed at half of the thickness of the plate. 


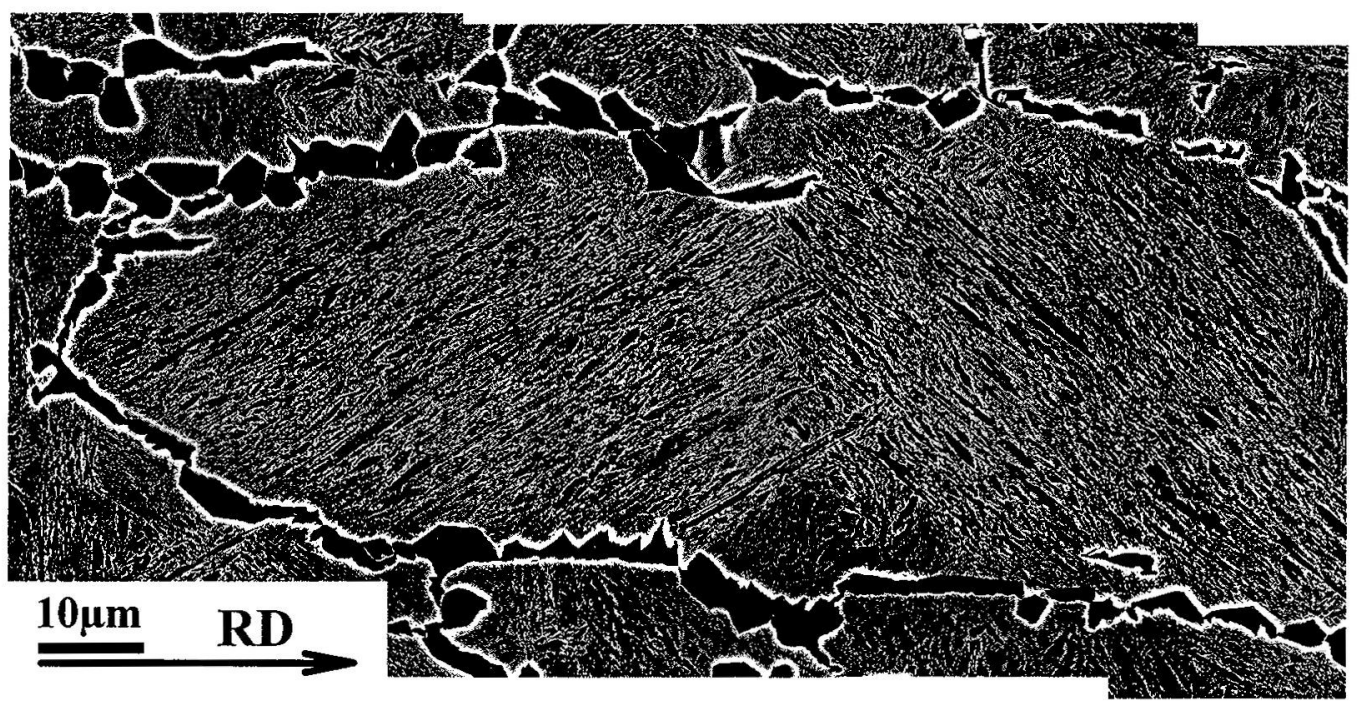

Figure 6: SEM micrograph of a representative area of the microstructure when $25 \%$ rolling reduction is performed at $750^{\circ} \mathrm{C}$, followed by air-cooling to $650^{\circ} \mathrm{C}$ and water-quench. Intermediate air-cooling was conducted to slightly form proeutectoid ferrite at austenite grain boundaries for facilitating their detection after quench. The plane of section is transverse to the plate along the rolling direction $(\mathrm{RD})$. The region studied is located at half of the thickness of the plate.

\section{CONCLUSION}

The results obtained in this investigation are consistent with the growth of bainite by a displacive mechanism. The formation of bainitic ferrite is found to be strongly affected by hot-rolling in the austenitic region. With the occurrence of hot-deformation, the structure of the bainite laths switches from a chaotic configuration to a very ordered arrangement. This selective orientation of the laths is believed to result from the formation of dislocation walls, which confer to the bainite laths a macroscopic alignment and a dimensional refinement.

\section{Acknowledgements}

This research was partly supported by the Belgian State, Prime Minister's Office, Federal Office for Scientific, Technical and Cultural Affairs, under contract P4/33 Interuniversity Poles of Attraction Program. JVH acknowledges the FWO (Fonds voor Wetenschappelijk Onderzoek). PJ is grateful to Prof. J.J. Jonas of McGill University for numerous discussions and continuous interest.

\section{References}

1. O. Matsumura, Y. Sakuma, H. Takeshi, Trans. ISIJ 27570 (1987).

2. P. Van Houtte, in The "MTM-FHM" software system, Version 2, K.U.Leuven, Belgium, 1995.

3. Ph, Bocher, E. Girault, B. Verlinden, E. Aernoudt, submitted to ISIJ Int:

4. R.K. Ray, J.J. Jonas, Int. Mater. Reviews 35, 1 (1990).

5. J.J. Jonas, in Proceedings of the $7^{\text {th }}$ International Conference on Steel Rolling, Tokyo, 1998, in press.

6. H. Christoffersen and T. Leffers, Acta mater.46, 4093 (1998).

7. Q. Liu, D. Juul Jensen, N. Hansen, Acta mater.46, 5819 (1998).

8. H.K.D.H. Bhadeshia, Mater. Sci. Eng. A, 273-275, 58 (1999). 